\title{
RICOEUR, Paul. Identidade Frágil: Respeito ao outro e identidade cultural
}

\author{
Douglas Carré1 \\ Claudia Tiellet ${ }^{2}$ \\ Noeli Dutra Rossatto ${ }^{3}$
}

\section{Apresentação}

O filósofo Paul Ricoeur analisa o problema da identidade colocando a questão da memória, memoria pessoal e memória coletiva, no vai e vem entre o nível da pessoa e o da comunidade. O que torna a identidade frágil é a relação ao tempo e a confrontação com o outro sentida como ameaça. Uma violência fundadora muito sensível conduz a comportamentos onde se opõe os direitos da pessoa e a segurança institucional. Privado de sanções, o direito fica sob a guarda somente do protesto moral.

\section{Texto publicado em "Os direitos da pessoa em questão" Europe Europa 2000, publicação FIACAT.}

Estou feliz que nosso colóquio da Federação Internacional da ACAT tenha escolhido por tema a questão da identidade vinculada à do reconhecimento do outro. Esta questão, com efeito, nos coloca em face de uma grande complexidade. Esta se exprime numa forma interrogativa: quem somos nós? Mais gravemente, somos de saída, confrontados ao caráter presumido, suposto e pretendido das reinvindicações de identidade. Esta presunção se coloca nas respostas que visam mascarar a ansiedade desta questão. Quanto a questão de que? Quem sou eu? Nos opomos a responder "que"? a forma: eis o que somos, nós outros. Tais nós somos assim e não de outra maneira. A fragilidade da identidade que vai nos ocupar neste momento mostra-se na fragilidade das respostas "que?" pretendendo dar a receita de identidade proclamada e reclamada.

\footnotetext{
${ }^{1}$ Doutorando pelo Programa de Pós-Graduação em Filosofia da Universidade Federal de Santa Maria/RS (UFSM) - Bolsista CAPES. Graduado em Filosofia pela PUCRS e Mestre em Filosofia pela UFSM. douglascarre@hotmail.com.

${ }^{2}$ Doutora em Filosofia pelo Programa de Pós-Graduação em Filosofia da Universidade Federal de Santa Maria/RS (UFSM). aitaadv2@gmail.com.

${ }^{3}$ Doutor em História da Filosofia (Medieval), Universidade de Barcelona (UB, 2000). Professor titular do Departamento de Filosofia da Universidade Federal de Santa Maria (UFSM). rossatto.dutra@gmail.com.
} 


\section{A questão da memória}

Queria consagrar o primeiro grupo das minhas observações ao desdobramento da questão do plano pessoal e coletivo. A questão que? (quem?) pode ser colocada para a primeira pessoa do singular: a mim, eu, e a primeira pessoa do plural, nós ou nós outros. A legitimidade deste desdobramento tem sido tomada como prova na ocasião do problema da memória que vai representar um grande papel na nossa discussão da narrativa e da história.

No plano da memória a questão da definição da identidade não é fácil nesse sentido que, à primeira vista pelo mesmo, a memória poderá ser uma identidade não somente pessoal, mas íntima: lembrar-se é, de saída, lembrar-se de si mesmo. Isto é, aliás, a lição de Santo Agostinho nas Confissões e, novamente, na época moderna, do filósofo de língua inglesa, John Locke. No Ensaio filosófico concernente ao entendimento humano, este propõe identificar uns aos outros os termos da série: identidade, consciência, memória, si mesmo. Por identidade entende-se o primado do mesmo sobre aquele que chama diversidade e que nós chamamos alteridade; esta, em virtude do princípio segundo o qual uma coisa é o que é e não outra. Esta identidade de si mesmo, que pode seguir do átomo ao carvalho que permanece o mesmo da semente à árvore, culmina no si que se reconhece a si mesmo, no

momento da reflexão, através de diferentes lugares e tempos. É a memória que atesta a continuidade da existência e a permanência do si mesmo. Tomada radicalmente, esta série de questões não deixa espaço para qualquer coisa como uma memória coletiva e correlativamente pela ideia de identidade aplicada a grupos, coletividades, comunidades, nações. Quanto ao mais se trata de uma analogia possivelmente falsa. Ora a experiência comum é contrária a este puritanismo semântico. A memória não é somente rememoração pessoal, privada, mas também comemoração, memória partilhada. Nós a encontramos nos ensaios, nas lendas, nas histórias, onde os heróis são os povos, ao menos enquanto indivíduos; nós os vemos em nossas festas, com suas celebrações e rituais. Não somente a ideia da memória coletiva parece apropriada a uma experiência direta e imediata da memória partilhada, mas pode-se também legitimamente exigir se a memória pessoal, privada, não é em grande parte um produto social: pensemos no papel da linguagem da memória para a fase declarativa: uma lembrança se diz na língua materna, a língua de todos, nossas lembranças mais antigas, aquelas da nossa infância, nos representam misturas à vida dos outros, na família, na escola, na cidade; é, muitas vezes juntos, que nós evocamos a um passado dividido. Enfim, o exame de situações particulares como aquela da cura 
psicanalítica nos revela que a rememoração, a mais privada, não é fácil e pede a ser ajudada e até permitida, autorizada por outro. Breve, nossa memória é sempre misturada àquela dos outros. Para fechar rapidamente esta discussão prévia, gostaria de dizer que a atribuição da memória é uma operação muito complexa que pode ser efetuada em benefício de todas as pessoas gramaticais: eu me lembro, ele/ela se lembra, nós, eles e elas se lembram. Esta atribuição múltipla da memória será agora nossa guia na sequencia de nossas análises e autorizará um vai e vem incessante entre o nível da pessoa e aquele da comunidade. Este emaranhado, se vai ver, é tal que em certos casos a identidade coletiva colocará de modo mais vivo e mais inquietante o problema de sua justificação. Até mesmo sua purificação, sua pacificação, sua cura, tanto é verdade que nossas memórias coletivas, mais ainda nossas memórias próprias são memorias feridas e doentias. Esta questão da atribuição do direito igual da memória e através da memória de identidade as das pessoas e das comunidades, são provisoriamente regidas, podemos nos confrontar a dificuldade maior aquela da fragilidade de identidade. É no decorrer desta segunda fase de nossa investigação que vai se por a confrontação com a alteridade do outro, tanto no plano individual quanto ao plano coletivo.

\section{O que é que faz a fragilidade da identidade?}

É preciso nomear como primeira causa da fragilidade da identidade sua relação difícil ao tempo; dificuldade primária que justifica o recurso da memória enquanto componente temporal de identidade em conjunção com a evolução do presente e a projeção do futuro. Ora a relação ao tempo tem dificultado em razão do caráter equivoco da noção do mesmo implícito àquela da identidade. Que significa, com efeito, ficar o mesmo através do tempo? $\mathrm{Eu}$ me mensurei outrora a este enigma, pelo qual tenho proposto distinguir dois sentidos idênticos, o mesmo como idem, same, gleich, o mesmo como ipse, self, selbst. Pareceu-me que a manutenção de si mesmo no tempo repousa sobre um jogo complexo entre mesmidade e ipseidade, se ousarmos usar estes barbarismos; deste jogo equívoco, aspectos práticos e fáticos são mais repetidos que os aspectos conceituais e epistêmicos. Direi que a tentação identitária, a "direção identitária" como diz Jacques Legoff, consiste em repelir a identidade ipse sobre a identidade idem, ou se preferis, no deslizamento, na deriva, conduzindo o suplício próprio ou mantém a si mesmo na promessa para a rigidez inflexível dum caráter ou sentido quase tipográfico do termo. 
Paremos por um momento nesta primeira causa da fragilidade. Em virtude deste que vemos dizer sobre a implicação da memória individual e coletiva, esta questão difícil do tempo concernente a duas espécies de saídas da memória.

No plano individual nós aprendemos na psicanálise quanto é difícil fazer memória e comparar seu próprio passado. É pelos traumatismos, feridas afetivas, que o sujeito é preso; e seu declive, observa Freud num ensaio famoso intitulado "Rememoração, repetição, perlaboração (Errinern, Weiderholen, Durcharbeiten) é ceder a compulsão de repetição que Freud atribui as resistências do recalque. Nisto resulta que o sujeito repete seus fantasmas no lugar de os elaborar; muito mais ele os deixa passar para o ato nos gestos que ameaçam a ele e os outros. A analogia no plano da memória coletiva é evidente; as memórias dos povos são memórias feridas que obcecam a lembrança das glórias e das humilhações dum passado longínquo. Pode-se mesmo surpreender e se inquietar o que a memória coletiva presente uma versão caricatural desses acessos de repetição e de passagem ao ato sob a forma de obsessão de um passado infinitamente dominado. É preciso mesmo reconhecer que o trabalho da memória é mais difícil para conduzir ao plano coletivo quanto ao plano individual, e que as fontes que podem oferecer a cura analítica são aqui sem equivalência. Onde estaria a simétrica da transferência? E do colóquio? Quem é o psicanalista? Quem pode dirigir o trabalho de perlaboração (de working through) trabalhando através? A questão é ainda mais turbulenta embora junte-se a ideia do trabalho da memória aquela do trabalho do sofrimento. Esta aqui, diz um outro ensaio de Freud, consiste no tratamento emocional e a perda do objeto de amor e logo também um objeto de ódio. O sujeito é convidado a romper um a um os laços resultantes de seus investimentos libidinais sob a dura obrigação do princípio da realidade, oposto ao princípio do prazer. É o preço a pagar por um desinvestimento libertador, senão o sujeito é arrastado sobre a encosta que da dor conduz a melancolia, a depressão, onde a perda do objeto se junta aquela da estima de si mesmo, desse Ichgefühle, de que fala Freud. A este respeito, uma noção desta prova deve nos alertar: falando dos sujeitos melancólicos, Freud diz que suas “queixas são acusações" ("ihre Klagen sind Anklagen"). Tudo se passa como se o ódio de si mesmo se transforma em ódio do outro na funesta química da melancolia. Desta análise resulta que o trabalho sobre si mesmo da memória não vai sem o trabalho do sofrimento, o qual não se resume na deploração passiva, mas consiste num trabalho sobre a perda, impulsionado até a reconciliação com o objeto perdido em termo de sua inteira interiorização. 
Os paralelos ao plano da memória coletiva não falham; a noção do objeto perdido encontra uma aplicação direta nas "perdas" que afetam também o poder, o território, as populações, que constituem a substancia do Estado. As dificuldades que fazem a dor são mesmo mais graves do que o plano individual. Daí o caráter equivocado das grandes celebrações funerárias em torno das quais um povo machucado se reúne. A frase "ihre Klagen sind Anklagen" soa de maneira sinistra. O fato turbulento é que a memória das feridas é mais longa e mais tenaz ao plano coletivo do que ao plano individual; os ódios são milenares e inconsoláveis. A impressão excedida que elas dão: demasiada memória aqui, demasiado esquecimento lá. A mesma memória repetitiva, a mesma memória melancólica, conduz uns a passagem ao ato visível das violências que não ficam simbólicas, e outro a

repetição assassina das feridas antigas. É no plano da memória coletiva, mais ainda aquela da memória individual que se confronta o trabalho da dor e o trabalho de lembrança toma todo seu sentido. Tratando-se de feridas de auto-estima nacional, podemos corretamente falar de um objeto de amor perdido. É sempre com perdas que a memória ferida é forçada a se confrontar. Aquele que não sabe fazer esse trabalho que prova que a realidade lhe impõe: o abandono dos investimentos pelos quais a libido não cessa de ser religada ao objeto perdido quanto a perda não seja totalmente interiorizada, mas é também o lugar de sublinhar que esta submissão a prova da realidade constitui verdadeiro trabalho da dor, do sofrimento, faz também parte integrante do trabalho da lembrança.

Concernente ao componente melancólico dos problemas da memória coletiva, nos pode preocupar a ausência de paralelismo no plano terapêutico. Tudo o mais se pode fazer apelo à paciência a respeito dos outros e de si mesmo; o trabalho do sofrimento não pede menos tempo do que o da memória.

\section{Outro ressentido como uma ameaça}

Evocarei agora uma segunda fonte de fragilidade de identidade: a confrontação com o outro sentida como uma ameaça. É um fato que o outro, por ser outro, venha a ser percebido como um perigo para a identidade própria, para a do nós e para a do eu. Pode-se estar certo sem surpreender: é preciso portanto que nossa identidade seja frágil, ao ponto de não poder suportar, não ser capaz de sofrer, que outros tenham modos diferentes de levar sua vida, de se compreender, de inscrever sua própria identidade na trama de viver juntos? Isto é assim. Estas são as humilhações, os ataques reais e imaginários a autoestima sob os golpes da 
alteridade mal tolerada, que fazem passar da acolhida a rejeição, a exclusão, o relatório que o mesmo mantém com o outro.

É possível analisar mais adiante esta reação hostil do outro? Pode-se, talvez, ali encontrar uma raiz biológica na defesa imunitária do organismo, como se vê na rejeição do intruso no caso do transplante; o organismo defende ferozmente sua identidade: duas exceções, são mais que exceções: o câncer e a gestação de embrião. A esse respeito, a aids propõe um exemplo perturbador da astúcia do intruso que negocia a quebra de bloqueios de imunidade. Acontece aqui alguma coisa nas fronteiras da célula e do organismo; operações de reconhecimento e de identificação desenrolam-se, regradas, por códigos precisos. Essa defesa de identidade toma formas propriamente humanas desde que intervenha o fenômeno da língua. A despeito de sucessos relativos de tradução e de mudanças linguísticas, as línguas não são hospitaleiras umas às outras. Passa-se a esse nível qualquer coisa comparável à defesa imune ao plano biológico; ora a linguagem constitui a mediação essencial entre a memória e o relato. As minorias articulam-se nos relatos: Hannah Arendt diz algo que a narrativa diz o "que" da ação. Pois o relato constitui facilmente fechamento da identidade numa memória sobre ela mesma: minhas lembranças não são as vossas; se necessário exclui as vossas. Para complicar as coisas, o sentimento de ameaça, resultante de uma alteridade mal tolerada, se junta à relação da inveja que não faz nenhum obstáculo ao reconhecimento do outro. A inveja, diz um dicionário, consiste num sentimento de tristeza, de irritação e de medo contra aquele que possui um bem que nós não temos. A inveja torna intolerável a felicidade dos outros. A dificuldade de compartilhar infortúnios se acrescenta à recusa de partilhar a felicidade. Precisaria aqui mostrar como, no lado passivo da inveja, uma forma de tristeza é acrescentada ao lado ativo da rivalidade na possessão; sobre o desejo de usufruir uma vantagem, de um prazer igual àquele de um outro, René Girard construiu sua teoria numa mimesi e sua interpretação do fenômeno do bode expiatório como desenlace da rivalidade mimética resultante da reconciliação de todos contra um.

Estes fenômenos de defesa, de rejeição, de inveja, nos convidam a transpor a distância entre identidade individual e identidade coletiva; o fenômeno nuclear é de caráter ameaçador pela integridade de si mesma que constitui a simples existência de um e de outro diferente de mim. Desta ameaça surgiu uma escala imensa no plano coletivo. As coletividades também são um problema de defesa imunitária quase biológica. É mesmo nesta grande escala que se deixam ler fenômenos que não tem quase equivalência no plano pessoal, se não pela transferência inversa do plano coletivo ao plano da identidade pessoal. Trata-se 
de fenômenos de manipulação que se pode atribuir a um fator inquietante e multifacetado que é interposto entre a reivindicação identitária e as expressões públicas de memória. $\mathrm{O}$ fenômeno permaneceu ligado com a ideologia onde o mecanismo fica habitualmente oculto; ao contrário da utopia, com a qual a ideologia merece ser acoplada, é inconfessável, ele se mascara voltando na denúncia contra os adversários no campo da competição entre ideologias; é sempre o outro que mofa na ideologia. A mais, operasse em níveis múltiplos. Por mais perto da ação ela constitui uma estratégia indispensável na qualidade como mediação simbólica revelando uma "semiótica de cultura" (Geertz): é para este título do fator de integração que a ideologia pode desempenhar um papel de guardiã de identidade. Mas esta função de salvaguarda não vale sem manuseios (manejos) de justificação num sistema de ordem ou de poder que trata formas de propriedade, aquelas da família, da autoridade, do estado e da religião. Todas as ideologias em definitivo giram em torno do poder. Dalí passa-se naturalmente aos fenômenos mais aparentes de distorção da realidade dos quais os adversários gostam de acusar-se mutuamente.

Vê-se em seguida de que nível as ideologias podem intervir no processo de identificação por si mesmo numa comunidade histórica: no nível da função narrativa. A ideologia da memória torna-se possível pelas fontes de variação que oferece o trabalho da configuração do relato. Toda narrativa é seletiva. Não se pode relatar tudo, mas somente os momentos salientes da ação que permitem a montagem da intriga, que dizem respeito somente aos acontecimentos relatados, mais os protagonistas de ação, os personagens. Nisto resulta que se pode sempre relatar de outra maneira. É esta função seletiva do relato que oferece para manipulação a ocasião e os meios de uma estratégia astuta que consiste na saída de uma estratégia de esquecimento tanto quanto de rememoração. Estas estratégias revelam tentativas exercidas por certos grupos de pressão que sobem ao poder através da oposição, ou refugiados nas memórias agitadoras, para impor uma história "autorizada", uma história oficial, aprendida e celebrada publicamente. Uma memória exercida, de fato, é no plano institucional uma memória ensinada; a memorização forçada se encontra assim enrolada no benefício da rememoração das peripécias da história comum realizada pelos acontecimentos fundadores da identidade comum. O fechamento do relato é montado assim ao serviço do fechamento identitário da comunidade. História ensinada, história aprendida, mas também história celebrada. A memorização forçada se junta às comemorações conhecidas. Um pacto terrível se arma assim entre rememorização, memorização e comemoração. Esta posse sobre 
a história não é a especialidade dos regimes totalitários; ela é o apanágio de todos os zelos da glória.

Temos dito bastante a respeito desta segunda causa da falibilidade da memória e de sua exploração ideológica. Umas das réplicas para estas manipulações é procurar em nível mesmo onde elas exercem privilégio. Aquele do fato. Pode-se sempre contar em outras palavras, vamos nós dizer. Mais precisamente este recurso não é somente oferta a distorção dos fatos, mas também à crítica da manipulação. Relatar de outra maneira confrontando fatos divergentes como as histórias tem ensinado para fazer no plano da crítica das testemunhas, relatos tornados documentos e arquivos. Confrontar os fatos é primeiro deixa-los relatar pelos outros e em particular deixar relatar pelos outros nos ensaios fundadores e assim ter acesso para uma montagem de intriga diferente dos acontecimentos que são a base de nossas celebrações comunitárias ou nacionais. Nós aqui tocamos as correções que a história pode exercer em relação da memória. Além disso sua amplitude no espaço e no tempo, a história leva o aguilhão da comparação a favor daquele somos convidados a reinterpretar nossa identidade em termos da diferença em relação as identidades adversas. É sobre este caminho que pode ser retornado contra si mesma a tendência inicial para sentir a confrontação com o outro como uma ameaça para a identidade própria, a nossa como a minha. "Confortar a sua identidade sem recusar o do outro e sem o maltratar" diz o título da nossa seção. Este relato crítico pode fazê-lo para o encontro dos relatos da loucura (irracionalidade) identitária.

\section{A herança da violência fundadora}

Eu queria, para finalizar, evocar uma última causa da fragilidade da identidade, a herança da violência fundadora. Esta última consideração nos aproxima das preocupações principais da nossa Federação Internacional da ACAT: a tortura. Nós a enquadramos no contexto maior evocando isto, chamo a herança da violência fundadora. Este é um fato que não existe na comunidade histórica que não seja um fato, pode-se dizer original à guerra. Este que nós celebramos sob o título de acontecimentos fundadores, são essencialmente atos violentos legitimados após golpe por um estado de direito, e, ao limite por sua antiguidade, por sua velhice. Não é um acaso que os fundadores da filosofia política, Hobbes, como cabeça (em frente) colocou o medo da morte violenta à base do reflexo seguro sobre o qual se enxertam as formas variadas e divergentes do princípio da soberania. No sentido forte da palavra é a seguridade que os indivíduos esperam do Estado de que modo isso procede na 
sua réplica pelo medo da morte violenta no nível institucional. Evocar este medo lembra o lugar da morte na gênese da política. Pode-se perguntar legitimamente se esta cicatriz tem jamais sido eficaz mesmo nos Estados de direito. As marcas da violência são por toda parte visíveis. Este é um plano individual, a persistência do espírito de vingança no coração do espirito de justiça. $\mathrm{O}$ Estado tem desarmado os cidadãos privando-os da possibilidade de fazer justiça por si mesmo; mas tem concentrado entre suas mãos o exercício da violência como legítima; toda punição, também proporcionada, seja ela ao delito, ou ao crime adiciona um sofrimento àquele infligido ao agressor. E, entre as sanções, a pena de morte justificada no inicio do século em toda Europa continua praticada em vários Estados, aliás, democráticos para dizer que o exercício da morte violenta não tem sido erradicado nos Estados de direito.

Numa discordância de um tipo particular se propõe aqui, que distingue de modo radical o plano político do plano privado na ordem das relações exteriores. Saber que os comportamentos de hostilidade entre os povos ou seus Estados são de uma outra ordem do que as relações de inimizade entre particulares. Estes ficam acessíveis ao compromisso à transição. No nível dos Estados prevê a relação amigo inimigo, que assola nas situações ou o pré suposto ou a integridade da comunidade estão em jogo. Sabe-se, segundo um pensador político como, Carl Schmitt falou nesta linha de pensamento. O que pensar, o problema agudo da guerra e do seu direito cruel fica ponderado. Que dizer, em particular, da licença dada ao assassinato nos Estados de guerra? Matar não é somente permitido, mas comandado. Ora, sabemos bem que está sob a cobertura do pretenso direito de guerra que a tortura tem sido e é ainda praticada. Certos limites desse pretenso direito tem sido emposto pela comunidade internacional como título de crimes de guerra, para não dizer genocídio e crimes contra a humanidade. Ora, a tortura e os tratamentos desumanos figuram entre os crimes de guerra. Mas este direito fica privado de sanções e fica sob a guarda da somente moral protestada. Pelo menos devemos saber porque protestamos e militamos. É em nome da ideia da dignidade de todo ser humano, menos culpado; sem direito pela consideração. Pois, atrás do sofrimento (do fazer sofrer) esconde-se a humilhação que quereria que o outro perseguido perca o respeito de si; se engane.

Aqui meu discurso junta-se àquele dos outros oradores deste colóquio e de todos os participantes. publicação FIACAT. 